\section{Estimating Mortality and Economic Costs of Particulate Air Pollution in Developing Countries: The Case of Nigeria}

Natina Yaduma, Mika Kortelainen, Ada Wossink

August 2012

\section{Abstract}

The value of statistical life is an essential parameter used in ascribing monetary values to the mortality costs of air pollution in health risk analyses. However, this willingness to pay estimate is virtually non-existent for most developing countries. In the absence of local estimates, two major benefit transfer approaches lend themselves to the estimation of the value of statistical life: the value transfer method and the meta-regression analysis. Using Nigeria as a sample country, we find that value transfer estimates are considerably lower, and more sensitive to specification than are estimates from the meta-regression More importantly, the latter method is better tailored than the former to incorporate many characteristics that vary from the study sites to the policy site and is therefore likely to provide more accurate value of statistical life predictions for very low-income countries. Using the meta-regression method, we find Nigeria's value of statistical life estimate to be $\$ 489,000$. Combining this estimate with dose response functions from the epidemiological literature, it follows that if Nigeria had mitigated its 2006 particulate air pollution to the World Health Organisation standards, it could have avoided at least 58,000 premature deaths and recorded an avoided mortality related welfare loss of about $\$ 28$ billion or 19 percent of the nation's GDP for that year.

JEL Classification Codes: I18, Q28, Q53, Q56

Key words: air pollution, value transfer, dose response function, meta-regression, $\mathrm{PM}_{10}$ value of statistical life

\section{Introduction}

As economies intensify production and consumption activities with the aim of achieving growth and development, these activities often move in tandem with external consequences posing a dangerous threat to human health and the environment. In particular, the harmful effect of air pollution (AP) on human health is an issue of global concern. The epidemiological literature has established links between particular air pollutants and human health risks, such as respiratory and cardiovascular diseases. However, in order to aid in setting priorities for public decision making, policy makers are not merely concerned about the linkage between AP and adverse human health but more about facts relating to the costs and benefits of mitigation. Policy makers are often confronted with a choice of how resources should be allocated to pollution control and therefore environmental management, education, health care, infrastructural development and a variety of other pressing economic needs. Consequently, a benefit-cost assessment of the health and economic costs of AP is an essential input in public decision making. If potential mitigation benefits are substantial, this would highlight the necessity of incorporating environmental management into a nation's developmental policies.

There exist different types of air pollutants - particulate matter (PM), methane, nitrogen oxide, sulphur dioxide and ozone amongst others. Among these pollutants, recent studies have consistently identified PM as the most hazardous to human health. Chronic exposure to PM exacerbates respiratory and cardiovascular diseases such as common flu, pneumonia, bronchitis and asthma (see Ruckerl et al., 2011). These may lead to premature mortality. The monetised mortality cost of particulate pollution accounts for approximately 90 percent of its total health cost (see Ostro, 2001; Akbostanci et al, 2009; Dickie and List, 2006; Zhang et al., 2008). These estimates explain why epidemiological and environmental economic analysts place much importance on PM and its mortality effect. Particles are measured in micrograms per cubic meter $\left(\mu \mathrm{g} / \mathrm{m}^{3}\right)$ of air sampled and $\mathrm{PM}_{10}$ is the most common measure of inhalable PM, defined as solid particles with an aerodynamic diameter of less than or equal to ten micro-meters (Pope, 2007). 
The most reliable way of measuring the mortality effect of AP in a particular area is to conduct epidemiological studies for that area. To capture both acute and chronic effects, ${ }^{1}$ a large cross-section of individuals should be studied prospectively for at least ten years, measuring both the AP concentrations to which they are exposed and other factors that affect the risk of death - smoking habits, family history, and body mass index amongst others (Cropper and Simon, 1996). Associated with the quantification of mortality effects is its corresponding monetisation into an economic cost. This process employs the value of a statistical life (VSL), a fundamental concept commonly used by environmental economists in analysing fatal risks of AP. The VSL represents an individual's or society's willingness to pay for a marginal reduction in the risk of dying (see for instance Viscusi and Aldy, 2003). ${ }^{2}$ This paper focuses on estimating the health related benefits associated with improving air quality in Nigeria. To do this well, we ideally would have primary data from which to estimate VSL, and then tie this to primary epidemiological data to translate the VSL estimate into a total benefits estimate. However, as both data collections are costly and time-prohibitive, we often rely on benefit transfer, which is an approach for estimating the costs and benefits of policies in the absence of original data collection. It transfers mortality effect and VSL estimates from one or more already completed studies - often termed the study site - to predict the health and economic benefits from the mitigation of pollution at a different point in space, time or both the policy site. Environmental analysts have increasingly used benefit transfer in cost benefit analyses, particularly those pertaining to non-market valuation (see for instance Boyle et al., 2009; Navrud and Ready, 2007; Pearce et al., 1994).

There are three major benefit transfer approaches used in eliciting willingness to pay for fatal risk reductions: preference calibration, value transfer and meta-regression analysis. The preference calibration technique, which has only seen limited use, specifies a preference function and uses available benefit information to calibrate the function's parameters to match the existing benefit estimates (see Smith et al., 2002 for more details). The value transfer method transfers and calibrates either a point VSL estimate, a measure of central tendency from a group of original willingness to pay studies - usually the mean - or administratively

Acute effects associate short term changes in exposure to air pollution and mortality; and chronic effects evaluate the mortality effects across communities or neighbourhoods with different levels of air pollution over longer periods (see Pope, 2007 for details).

Common approaches to estimating the VSL include stated preference surveys where respondents are asked to make trade-offs between mortality risk and monetary consequences, and revealed preference approaches such as through assessing workers' trade-offs between wages and job-related risks. approved VSL estimates from a developed country, particularly the US (see for instance Rosenberger and Loomis, 2003). This is the most convenient benefit technique to transferring estimates from study site to policy site (Navrud and Ready, 2007). The meta-regression analysis is a statistical method that combines the results of several VSL studies to provide a VSL prediction function, to be used for an out-of-sample approximation. The use of metaregressions for function transfers is gaining growing popularity in environmental and health economics research (see for instance Nelson and Kennedy, 2009; Bellavance et al., 2009). Evidence from previous studies supports the stylised fact that meta-regressions (or more generally function transfers) lead to more accurate predictions than value transfers (see for instance Boyle et al., 2010; Kaul et al., 2012; Rosenberger and Loomis, 2003). Contrary to this fact, a majority of health and economic cost studies conducted in the developing world - and a handful of studies in the developed world too - employ the latter technique in estimating policy site VSL (see for instance Zhou and Tol, 2005; Quah and Boon, 2003; Chestnut et al., 1997; Larson et al., 1999; Pearce, 1996).

To the best of the authors' knowledge, this paper is the first study that monetises the mortality related benefits associated with improving air quality in a developing country employing a VSL estimate provided by the meta-regression method. In addition, this paper extends upon an earlier meta-regression by Miller (2000) in three ways. First, by including developing countries in the sample, this study has a better representation of these countries in its regressions. Second, this study explores the use of additional regressors and statistical tests in determining its most preferred VSL meta-regression prediction function. Third, in contrast to Miller (2000), we employ a consistent estimator for the expected value of the VSL from metaregressions that use the log of VSL as the dependent variable. Accordingly, we improve on Miller's study by conducting this adjustment in the VSL prediction for Nigeria. Finally, and perhaps most importantly, the paper compares VSL estimates provided by both the value transfer and meta-regression approaches, investigating which of the two methods provides more credible VSL approximations for developing countries. We find the latter to be the superior method. Thus, the paper recommends the use of the meta-regression benefit transfer approach in health risk analyses in developing countries, if much more expensive and timeconsuming stated or revealed preference studies cannot be implemented. 


\section{Review of Literature}

2.1 A Roundup of Studies on the Value of Statistical Life and the Economic Cost of Particulate Pollution

Assessment of the economic costs of AP is a fairly new branch of research in the fields of environmental and health economics. While epidemiological studies have assessed the health costs of AP since the 1940s, it was not until the early 1990s that economists made an effort in assessing these costs. As earlier stated, the VSL is an individual's or society's willingness to pay for fatal risk reductions, thus involving a money-risk trade-off. There are at least three generally accepted ways of eliciting this trade-off. The first is a wage-risk study. This measures willingness to pay by estimating the compensation, in the form of wage premiums, demanded by workers for taking up riskier jobs. The second is consumer choice study which investigates individuals' market decisions that reveal implicit values embedded in behaviour to reduce mortal risk; such as decisions to buy smoke detectors, bicycle or motor-cycle helmets and so on (see Miller, 2000). These two methods - wage-risk and consumer choice - are generally termed revealed preference techniques, with the former and latter eliciting individuals' risk taking preferences in the labour and product markets respectively. The third approach is to use stated preference surveys, which directly or indirectly ask respondents to make contingent trade-offs between mortality risks and monetary consequences.

Several studies employed these three valuation methods in estimating the VSL. For instance, Viscusi (2004) and Garbacz (1989) employed the wage-risk and consumer choice methods in estimating the US VSL as $\$ 5.9$ million and $\$ 3.0$ million, respectively. Similarly Ortuzar et al. (2000) used the contingent valuation method in estimating Chile's VSL as \$0.63 million. However, most of the available studies are from developed countries, particularly the US and UK. These money-risk trade-off studies were virtually non-existent for developing countries and it is only recently that a few have cropped up in China, India, Malaysia, Taiwan, Chile, Mexico and Thailand. Data scarcity on willingness to pay to avoid mortality or even on occupational risk and wages, and the huge costs involved in conducting these studies, plagues and constrains the emerging body of interesting work estimating the VSL in developing countries (Bowland and Beghin, 2001). Most of these studies used the wage-risk method and available estimates vary depending on the baseline and type of risk assessed, and the valuation method employed. Even in the face of identical risk reductions, these three valuation methods could lead to considerable variations in the money-risk trade-offs obtained. However, it is generally observed in the VSL literature that consumer choice studies tend to produce lower VSL estimates than the contingent valuation technique (see Bellavance et al., 2009; de Blaeij et al., 2003). Unlike the case of consumer choice and contingent valuation methods, there is no consensus on whether the contingent valuation technique provides higher or lower VSL estimates than the wage-risk method. However, Viscusi (2011) and Kochi et al. (2006) indicated the likelihood of the latter providing relatively higher estimates than the former.

Studies that estimated the benefits of AP control programs indicate that when monetary measurements for reductions in mortality effects are considered, the benefits of mitigation could be enormous (Chestnut et al., 1997). For instance, Quah and Boon (2003) estimate the mortality related welfare losses resulting from particulate pollution in Singapore for 1999. Employing the benefit transfer method via the transfer of dose response functions (DRFs) developed by Ostro $(1994)^{3}$ and a (value transfer) calibration of Singapore's VSL, the study estimates the total economic costs of particulate pollution as $\$ 3.7$ billion. ${ }^{4}$ This amount translates to about 4.3 percent of Singapore's GDP in 1999. Zhou and Tol (2005) employed similar benefit transfer techniques in estimating the mortality related welfare losses arising from particulate AP in Tianjin, China, for 2003. They estimate this as $\$ 1.1$ billion, with mortality cost accounting for 80 percent of this amount and the remaining attributable to morbidity cost - such as cost of chronic bronchitis, asthma, and pneumonia amongst other particulate AP related diseases. ${ }^{5}$ This amount represents 3.7 percent of Tianjin's GDP in 2003. Such substantial mortality related welfare losses to Singapore and Tianjin imply that the mitigation of particulate AP might yield substantial welfare gains that are equal to a significant percentage of these economies' GDPs. Consequently, this research suggests a need for these previously mentioned economies to incorporate environmental management into their developmental policies.

Dose response functions show a relationship between exposure to a given concentration of an air pollutant and the resulting mortality effect from that concentration level. See methodology section of paper for more details.

Adopting the human capital and cost of illness approach, these economic costs could be interpreted as productivity losses brought about by pre-mature mortality resulting from air pollution. Consequently, this paper uses the terms economic cost and mortality related welfare losses interchangeably in its analysis of the monetised health costs of particulate pollution.

The estimates for Singapore and Tianjin are in US 1999 and 2003 dollars respectively. Except otherwise stated, all monetary estimates presented in this paper are in US 2006 dollars. 
Six decades ago, two devastating AP episodes sparked public awareness of the health impairing effects of outdoor particulate pollution, especially in highly polluted cities of the world. These were the toxic fogs in Donora, Pennsylvania (USA) between 25th and 31st October, 1948 and that of London between 5th and 8th December, 1952 that claimed 20 and 4000 lives respectively. These incidents drew global attention to the mortality effects of particulate pollution on human health (Pope and Dockery, 1994; Phalen, 2002). ${ }^{6}$ In spite of the fact that historical accounts of AP exposures in cities and work places prior to the 1990s were rarely accompanied by quantitative pollution data, an increasing number of deaths and sicknesses during these two major pollution episodes made obvious the fact that an association between (particulate) pollution and mortality exists (see Phelan, 2004; Pope and Dockery, 1994 for instance). In a bid to provide more compelling evidence on the association between outdoor particulate pollution and mortality, these pollution incidents launched a plethora of time series studies that observed changes in daily death counts linked with shortterm term changes in particulate pollution. Daily time series studies evaluate effects of shortterm exposure to pollution by analysing associations between changes in daily mortality counts with day-to-day changes in ambient pollution concentrations. Further, these studies relate mortality to several days of abnormally high concentrations of AP, for example the Donora and London fog episodes (see for instance Pope, 2007; Schrenk et al., 1949). Pope (2007) interestingly posited that despite the fact that studies of short-term exposure to particulate pollution are associated with mortality effects, these same effects are generally larger with intermediate and longer-term time scales of exposure. This is undeniably a logical argument. As long as an association between exposure to particulate pollution and mortality exists, the mortality risks of short-term exposure should be less than those of the long-term. ${ }^{7}$

There is uncertainty regarding the estimated deaths from these disasters, especially that of London because there was a concurrent influenza epidemic during that period. In addition, it is argued that other confounding factors such as the correlation between PM and other air pollutants, temperature and high humidity could have also been responsible for the deaths (Holland et al., 1979). Nevertheless, most estimates attribute at least 3,000 deaths to the London fog (see for instance Stern, 1977; Clayton, 1978).

In his review of studies analysing time variations in response to exposure to particulate pollution, Pope (2007) found that incremental increases of a $20 \mu \mathrm{g} / \mathrm{m}^{3}$ of $\mathrm{PM}_{10}$ are associated with approximately a 0.4 to 1.3 percent and a 6 to 17 percent increase in relative risk of mortality due to short-term and long-term exposures, respectively. Hence, the mortality effects of short-term exposure are glaringly less than those of the long-term.
Subsequently, a handful of long-term (and intermediate) exposure studies investigate whether or not the mortality effect of short-term exposure to particulate pollution may be due to a phenomenon called 'mortality displacement' or 'harvesting effect. ${ }^{8}$ Dominici et al. (2003) set out to investigate this phenomenon using different timescales of variation in AP time series. This analysis found larger relative rates of mortality associated with particulate AP at longer timescale variations - 14 days to 20 months - than at shorter timescales -1 to 4 days. Also, Schwartz (2000, 2001 and 2003) applied smoothing techniques to decompose data into different timescales and arrived at a similar conclusion as Dominici et al. (2003). Hence, recent epidemiological studies do not only confirm the association between particulate AP and mortality but also show that long-term exposure to particulate pollution is associated with larger mortality effects than short-term exposure. This evidence refutes the suggestion that mortality effects of short-term exposure are due to mortality displacement. Despite the fact that temporal proximity in exposure matters, with the latest exposure having the largest mortality effect, empirical evidence suggests that short-term exposure studies of particulate pollution only capture a fraction of the overall effects of long-term repeated exposure to particulate pollution. The overall epidemiological evidence suggests that mortality effects are dependent on both exposure concentrations and duration of exposure, and that long-term exposures have larger, more persistent cumulative effects than short-term exposures (Pope, 2007). Appraising these studies reveals that similar associations between particulate AP and mortality were found despite the differences in methodologies employed and samples investigated. Furthermore, the most recent studies appear to show similar associations with those of the great AP episodes despite the fact that average concentration of particulate pollution has been on the decline, especially in the developed nations (see for instance Pope et al., 1995; WHO, 2003).
Mortality displacement, in this context, refers to the temporal change in the mortality rate of a particular population usually attributable to short-term pollution episodes. For instance, during the 1952 London fog, an excess mortality rate - especially among the older and sick people - was recorded. This might therefore imply that the fog greatly affected those whose health was already impaired and would have died in the short-term anyway. Hence, the excess deaths after the fog episode would be accompanied by a short-term compensatory reduction in deaths. 


\section{Methodology and Data}

3.1 The Value of Statistical Life

The huge costs - in terms of resource, expertise and time - associated with the direct elicitation of the VSL has limited the use of direct estimation in the developing world. Thus, there is a need for an affordable and credible means of estimating willingness to pay for fatal risk reductions for the third world. This has led environmental researchers in these countries to increasingly use two major benefit transfer techniques - the value transfer method and metaregression analysis - without costly direct estimations (Miller, 2000). Conventionally, the value transfer method simply calibrates a VSL estimate transferred from a developed country, particularly the US, based on income differences between the country undertaking the adjustment and that in which the estimate is transferred. Virtually all health and economic cost studies conducted in developing countries have employed this method in estimating the VSL. This technique obtains a VSL estimate for Nigeria using the following equation:

$$
V S L_{N I G}=V S L_{U S} *\left(\frac{Y_{N I G}}{Y_{U S}}\right)^{e},
$$

where $V S L_{N I G}$ is Nigeria's VSL estimate to be obtained via calibration; VSLUS is the US VSL estimate to be transferred to Nigeria; $Y_{N I G} / Y_{U S}$ is the ratio of purchasing power parity (PPP) ${ }^{9}$ of Nigeria's GNI per-capita to that of the US (at 2006 prices); and $e$ is the elasticity of willingness to pay for a marginal reduction in mortal risk with respect to income. This is assumed arbitrarily to be 1.0 in most empirical studies estimating the health related benefits associated with mitigating air pollution in developing countries (see for instance Zhang et al., 2008; Hainoun et al., 2010; Sakulniyomporn et al., 2010). ${ }^{10}$

The apparent simplicity renders the value transfer procedure an attractive approach but it is not without flaws. Although the income elasticity of marginal risk reduction has been (assumed to be) unity in most empirical studies, there is no consensus on the choice of this

The PPP measurement of GNI presents GNI based on the price of the market basket of goods and services in one country relative to the US, thus, equating the difference in the purchasing power of a dollar in all countries.

It is worth nothing that the formula in equation (i) is typically used in obtaining VSL value transfer estimates (see for instance Quan and Boon, 2003; Zhang et al., 2008; Zhou and Tol, 2005). Thus, the same formula could be applied to another country by substituting Nigeria's GNI per-capita with that of the country being investigated. parameter in the literature. In practice, this parameter is not necessarily constant but can vary depending on the income level of the country under investigation. In fact, most empirical studies conducted in both the developed and developing worlds estimated $e$ to lie between 0.46 and 2.3 (see Bellavance et al., 2009). With precise reference to Nigeria (and other countries with very low GNI per-capita), the choice of $e$ is of prime importance in the calibration process because of the large income disparity between Nigeria, and the US. For instance, a low income elasticity - say 1.0 - will lead to a much higher VSL estimate for Nigeria than a high elasticity - say 2.0. In order to cover the uncertainty in the choice of this elasticity parameter, Robinson and Hammitt (2009) suggest the use of three estimates - lower, central and higher respectively given by 1.0, 1.5 and 2.0 - in health risk analyses conducted in the third world. We incorporate this suggestion in our value transfer analysis. However, it is pertinent to note that very little empirical evidence exists regarding the accuracy of the value transfer method, and it still remains uncertain whether it yields a larger or smaller calibration relative to what would have been obtained if more rigorous VSL studies were conducted in countries employing the method (see for instance Chestnut et al., 1997).

More importantly, the value transfer technique implicitly assumes that income disparity between countries is the only factor responsible for differences in willingness to pay for fatal risk reductions across national boundaries. In addition to income, which has been observed to be a major determinant of the VSL, ${ }^{11}$ other factors are likely to affect VSL; for example mortality risks posed by AP and public awareness of the dangers of these risks and demographic factors such as life expectancy. The value transfer procedure fails to capture the importance of these (and other) factors in its VSL calibration. Employing meta-regression analysis, we incorporate these additional factors accounting for differences in willingness to pay for fatal risk reductions between countries in obtaining a VSL prediction for Nigeria. We then compare the estimates derived from both the value transfer and meta-regression techniques to choose the most preferred estimate for monetising mortality cost in Nigeria.

The meta-analysis in this paper follows and advances Miller's (2000) study. In spite of the fact that the literature clearly identifies (fatal) risk and income as major determinants of VSL, Miller (2000) considered the latter variable only in his regressions. We extend Miller's

VSL and income have been observed to have a positive and significant relationship in virtually all studies that have explored the relationship between the two (see Miller, 2000; Viscusi and Aldy, 2003; Bowland and Beghin, 2001. 
(2000) framework by controlling for mortal risk and other exogenous factors that could potentially affect the VSL. The paper also employs controls for study type - consumer choice (CC), contingent valuation (CV) and wage-risk (WR) - to enable the impact of the estimation technique on VSL differentials to be analysed. In obtaining a VSL prediction function for Nigeria we use the VSL estimates primarily obtained from developed countries, and a few from developing countries. Further, to control for additional country characteristics and to test the importance of including developing countries' VSL estimates in the meta-regression sample on the differential in income elasticity of VSL between developed and developing countries, we define a binary variable " $d$ "; where $d=1$ and $d=0$ for former and latter countries respectively. We then interact this variable with income; the coefficient for the interaction term gives the difference in income elasticity of VSL between the two groups of countries. The paper's metaregression analysis takes into account differences in income, fatal risk, educational level, development levels and demographics between countries (see for instance Wang and He, 2010). As a result, we assume the following functional form and regression equation respectively:

$$
\begin{gathered}
V S L=f(\text { gnipc }, \text { risk }, \text { educ, age }, C C, C V, W R, d, \text { gnipcd })+\varepsilon \\
V S L_{i}=\beta X_{i}+\varepsilon_{i}, \quad i=1,2, \ldots, n
\end{gathered}
$$

where, as earlier defined, VSL is the value of statistical life; $\beta$ is a vector of slope and intercept parameters to be estimated; $X$ is a vector of regressors including GNI per-capita in PPP terms (gnipc), mortal risk (risk), education (educ), age (age), the study type binary variables - CC, CV and $W R$ (with $C C$ being the base group), $d$ and gnipcd are the developed country binary variable and its interaction with income respectively; $\varepsilon$ is the random error term; $i$ is an individual observation (study) and $n$ is the total number of observations in the sample.

We employ the following variables to control for the various factors discussed above.

1. GNI per-capita in 2006 PPP terms is used in capturing income in equations (ii) and (iii) as well as in the value transfer equation (i).

2. Crude mortality is used as a proxy for risk. VSL estimates vary due to different baseline risks employed in VSL investigations. An increase in baseline risk assessed leads to an increase in VSL, ceteris paribus (Hammitt, 2000). The type of fatal risk assessed and the method of valuation employed in these assessments are also likely sources of variation in VSL estimates. It is therefore not a coincidence that the cross country VSL estimates in our sample have a considerable variation. These differences in baseline, types and methods of assessing risks and the unavailability of case specific risk data for Nigeria pose a systemic challenge for the use of one fatal risk variable that unifies all these differences. Thus, we aggregate the different risk concerns under the unifying heading "mortality risk" and employ the crude mortality rate of each country as a proxy for this.

3. The average years of education of each country in the sample, school life expectancy, is used to capture individuals' awareness of different kinds of mortal risk. The reasoning here is that the more aware of these dangers people are, the more likely they are to pay for a reduction in mortal risks and vice-versa.

4. Life expectancy at birth captures average age of individuals in each country. The VSL literature recently recognised the importance of individuals' life expectancy in explaining willingness to pay for health risk reductions. Remaining life expectancy at older ages is lower than that of younger ages, hence, reducing the number of future years at risk as people age. Therefore, the benefit of a unit decrease in current period mortality risk declines overtime (Hammitt, 2000). This should reduce older individuals' willingness to pay for fatal risk reduction than that of younger individuals, ceteris paribus. Conversely, the opportunity cost of spending on fatal risk reduction declines with age as individuals' savings accumulate, especially during the phase they earn comparably higher incomes in their career cycle (see for instance Muller and Mendelsohn, 2007; Hammitt, 2000). Similarly, many analysts would argue that a society would pay more for a regulation that saves a particular number of young people than one that saves the lives of the same number of senior citizens. It is worth noting that the literature dictates no consensus on the effect of age on willingness to pay for risk reductions as various authors have found both positive and negative relationships between the two (see for instance Viscusi and Aldy, 2007; Hammitt, 2000)

Based on equation (iii) and following Miller (2000), we estimate a double-log model, that is $\ln \left(V S L_{i}\right)=\beta\left(\ln X_{i}\right)+\varepsilon_{i}$. In addition, we estimate a semi-log model, that is $\ln \left(V S L_{i}\right)=\beta X_{i}+\varepsilon_{i}$. The use of the two functional forms broadens the range of benefit transfer models to be assessed (Miller, 2000). In the estimation of these functions we employ individual t-tests and F- 
tests of multiple exclusion restriction in determining which regressors can be excluded from the model. The preferred specification is premised on the model providing a VSL prediction with statistically significant regressors only. Afterwards, we employ the Davidson-Mackinnon test for non-nested models (see Wooldridge, 2008) in choosing which of the preferred specification under the two functional forms is more suitable for estimating Nigeria's VSL.

After estimation of the VSL prediction function, the Nigerian prediction is obtained by inputting the Nigerian values for the chosen regressors. The use of the three study type dummies provides three VSL estimates corresponding to the prediction provided by each of the study type. The coefficients of the $C V$ and WR variables capture the differentials in VSL prediction provided by each of these two methods and the base group, the consumer choice method. To avoid a proliferation of VSL predictions emanating from these study variables, we report the mean from the data to obtain one estimate. Further, as the regressand is in log form, the prevalently used approach in obtaining a prediction - exponentiation of the log predicted value - is an inconsistent estimator that underestimates the expected value. To obtain a consistent prediction, we adjust the commonly used method by employing the Smearing Factor Approach (see for instance Manning and Mullahy, 2001; Wooldridge, 2008). ${ }^{12}$ Miller (2000) did not incorporate this adjustment in his VSL prediction for countries of the world. As mentioned in the introductory section, this paper implements this retransformation in its VSL prediction for Nigeria. Consequently, we call this parameter the adjustment coefficient and the corrected VSL prediction obtained from this procedure the adjusted VSL (see details in the results for meta-regressions in results and discussion section).

This approach obtains a consistent prediction by multiplying the exponentiated log predicted value to the mean of the exponentiated OLS residuals from the regression (see for instance Wooldridge, 2008). It is pertinent to note that this adjustment does not rely on the OLS assumption of normally distributed errors because there is not much information available about the stochastic properties of the VSL estimates transferred to this study. Additionally, these estimates have been obtained by different researchers analysing different types of risk and at the same time using different specifications and techniques (Bowland and Beghin, 2001). See Manning and Mullahy (2001) and Wooldridge (2008) for details on other methods of conducting this adjustment with and without the normality assumption.
Assessment of the mortality costs and mortality related welfare losses arising from particulate AP starts with estimating mortality costs and then uses the results to compute its corresponding welfare losses. Like many earlier studies, this research closely adopts Ostro's (1994) DRF procedure in estimating the mortality cost of particulate pollution. ${ }^{13}$ The method has been well worked out over time with many panel studies and large national surveys (see for instance Dixon et al., 1994; Pope et al., 1995).

Ostro (1994) presented one of the most carefully executed meta-analyses of epidemiological studies on particulate AP and developed dose response coefficients (DRCs) for mortality health effects. Recent health cost analyses have relied on Ostro's (1994) DRCs and these have been largely employed in assessing mortality costs of AP on a global scale (see for instance Zaim, 1999; Resosudarmo and Napitupulu, 2004; Quah and Boon, 2003). Hence, just like similar studies using the benefit transfer approach, we assume the transferability of DRCs largely obtained from studies in the US to investigate the mortality cost of particulate pollution in Nigeria. The unavailability of indigenous DRFs and the cost advantages in terms of time and resources in providing estimates of DRFs justify the assumption of transferable DRCs. Health effect studies are very expensive to conduct and it would take years to replicate and interpret them before they are accepted by the scientific community (Chesnut et al., 1997). In addition, with particular reference to particulate pollution, there appears to be a consensus in DRFs as related studies provide a converging estimate (Quah and Boon, 2003). The few studies on DRFs

As earlier noted, the DRF shows a relationship between exposure to a given concentration of an air pollutant - dose - and the respective health effect - mortality - of the pollutant. In other words and with particular reference to this study, DRFs show the expected change in mortality per unit change in $\mathrm{PM}_{10}$ concentration. A majority of epidemiological studies assume this relationship to be linear. The dose response relationship is often expressed as a percentage change in mortality due to a given change in a pollutant, $\mathrm{PM}_{10}$. Recall that in the case of $\mathrm{PM}_{10}$, the units of pollution are measured in $\mu \mathrm{g} / \mathrm{m}^{3}$ of air sampled. These are small amounts and the change in health outcome - mortality - is also very small per microgram change in pollution. Thus with an estimated dose response coefficient of 0.096 percent which is equal to a factor of 0.00096 , this implies that a single microgram change in $\mathrm{PM}_{10}$ pollution will have a very small impact on crude mortality rate the percent of population that dies each year.

Estimating a DRF requires a detailed measurement of exposure and damage and this process can be very costly - resource, expertise and time-wise (Glover, 2002; Zhang et al., 2008; Quah and Boon, 2003; Krupnick et al., 1993). The estimation procedure is undertaken in two ways; first, by following a given cohort of people through time and recording their health status. This is then related to a time series of pollution concentration data. Second, a cross-sectional technique is employed, for instance, correlating health data in different locations within or across cities with factors that are likely to explain variations in the health status and mortality. A majority of studies on AP related DRFs have been undertaken in the developed world, particularly the US and UK. 
conducted in the developing world suggest very similar DRCs to those derived in the developed world (see Khatun, 1997; Krzyzanowski et al., 2002).

Given the assumption of transferable DRFs, the following steps are used in estimating the mortality cost of particulate pollution:

1. Establish the annual average level of ambient $\mathrm{PM}_{10}$ concentration for the year under consideration, 2006.

2. Relate the concentration to mortality using DRFs.

3. Relate the DRFs to the stock at risk; the Nigerian population in 2006.

The general form of Ostro's (1994) DRF in estimating mortality damage from particulate pollution is:

$$
H_{\text {mortality }, P M_{10}}=b_{\text {mortality, } P M_{10}} * \text { crude mortality rate } * P O P_{i} * d P M_{10} \text {, }
$$

where $H_{\text {mortality, } P M 10}$ is the number of mortality cases caused by particulate pollution; $b_{\text {mortality,PM10 }}$ is the mortality DRC for particulate pollution; crude mortality rate is the number of deaths per 1000 individuals for the year 2006; $P O P_{i}$ is the population at risk of dying due to particulate pollution; and $d P M_{10}$ is the change in the ambient concentration of $\mathrm{PM}_{10}$, defined as the difference between an observed and a target level of $\mathrm{PM}_{10}$ concentration. We employ the WHO (2005) annual average $\mathrm{PM}_{10}$ air quality guideline of $20 \mu \mathrm{g} / \mathrm{m}^{3}$ in computing $d P M_{10}$.

Table 1 summarises PM 10 DRCs for mortality cost analysis estimated by Ostro (1994). The table presents three coefficients - lower, central and upper - for mortality effect associated with $\mathrm{PM}_{10}$. The use of these three estimates paves way for sensitivity analyses in mortality risk investigations. Given that these DRCs are mostly derived from studies conducted in the US, their transferability to the Nigerian investigation needs to incorporate factors that account for differences between the US and Nigeria. For instance, it would be rational to assume that the baseline health and medical care standard in the US is better than Nigeria's, hence, a greater susceptibility to the mortality effect of $\mathrm{PM}_{10}$ for the Nigerian population (see for instance Chestnut et al., 1997). Consequently, a given dose of $\mathrm{PM}_{10}$ concentration may pose more fatal hazards in Nigeria than the US. Incorporating this into our analysis, this paper transfers the central and upper coefficients of the DRCs presented in Table 1 as its lower and upper estimates respectively. ${ }^{14}$

Finally, to monetise the mortality cost estimate, we relate the most preferred VSL estimate - after comparing the estimate to be derived from the value transfer and metaanalytic techniques - to the mortality cost estimate to be obtained. Thus, mortality related welfare losses attributable to particulate pollution are estimated using the following equation:

$$
T C_{\text {mortality }, P M_{10}}=\operatorname{VOSL}_{N I G} * H_{\text {mortality }, P M_{10}},
$$

where $T C_{\text {mortality, } P M 10}$ is the total mortality welfare losses resulting from $\mathrm{PM}_{10}$ pollution and all other variables are as previously defined.

3.3 Data Sources and Summary Statistics

First, for the value transfer calibrations we adopt the US Environmental Protection Agency (USEPA) administratively approved VSL of $\$ 5.5$ million (1999 dollars) for the analysis of reduced mortality from air regulations (USEPA, 2004). This estimate approximates to $\$ 6.655$ million in 2006 dollars. Additionally, we employ the US average VSL estimate of $\$ 7.66$ million from our sample (see Table 3 ) in exploring further insights on the application of the value transfer calibration. Data on GNI per-capita in PPP terms for both Nigeria and the US are obtained from the World Bank's World Development Indicators (WDI, September 2010 edition).

Second, for the meta-regression analysis, estimates of VSL for different countries are drawn from literature reviews in the works of Viscusi and Aldy (2003) and Miller (2000), and more recent studies are obtained through key word searches using search engines such as Social Sciences Citation Index, ScienceDirect and Econ Lit. ${ }^{15}$ The VSL observations are estimates transferred from 83 individual VSL studies spread across twenty countries. The consumer By implication, the lower estimate of the mortality DRC presented in Table 1 will not be transferred to
this study due to the expected difference in baseline health and medical care standards between the US and Nigeria.

15 A majority of these VSL estimates are presented in different dollar years in their original studies. These estimates are converted to US 2006 dollars using the US Bureau of Labour Statistics CPI inflation calculator available online at http://data.bls.gov/cgi-bin/cpicalc.pl 
choice, contingent valuation and wage-risk methods account for 12, 21 and 50 VSL estimates in the sample, respectively. Given that the individual studies estimate VSLs for different samples in different countries, this paper assumes these individual study site estimates as independent (random) country-wide VSL draws across the countries the samples were investigated. This assumption allows matching these VSL estimates with the aggregate explanatory variables in our meta-regression model. More importantly, the assumption is needed given the objective of obtaining a meta-regression prediction for Nigeria's VSL. For all the countries in the sample, data on GNI per-capita in PPP (gnipc) and life expectancy at birth (age) are obtained from the World Bank's WDIs (September 2010 edition). Data for school life expectancy (educ) and crude mortality rate (risk) are respectively obtained from United Nations Statistics Division (2010) and World Bank (2010). ${ }^{16}$ The sample consists of 83 observations drawn from 20 countries, a very good proportion coming from the US (see Table 2 for data used in the study's metaregression analysis)

Additionally, for the health cost estimation, data on Nigeria's annual average PM $_{10}$ concentration and population are obtained from the World Bank's WDI (September 2010 edition). Data on Nigeria's crude mortality rate is obtained from the World Bank (2010) and estimates of mortality DRCs are transferred from the epidemiological literature - precisely from Ostro's (1994) study - using the benefit transfer approach. All estimations are for the year 2006.

Table 3 summarises the VSL estimates transferred for this paper's meta-analysis. The mean VSL for the 83 observations is $\$ 6.2$ million with a standard deviation (s.d) of 6.1 million. The US accounts for 33 of these studies with a mean VSL of $\$ 7.7$ million and s.d of 6.4 million respectively. The respective means for the UK, Canada, Sweden, India, New Zealand, South Korea and Thailand are \$6.7 million, \$8.2 million, \$4.3 million, \$0.3 million, \$2.2 million, \$1.2 million and $\$ 1.1$ million. ${ }^{17}$ The estimates for other countries in the sample may be less reliable as they are based on only two or less of such studies (Miller, 2000). This paper includes 12 VSL estimates from other developing countries in the sample, namely; China, Chile, India, Malaysia, Mexico and Thailand. This inclusion ensures a better representation of developing countries in

These data are available at http://unstats.un.org/unsd/demographic/products/socind/education.htm and http://data.worldbank.org/indicator/SP.DYN.CDRT.IN, respectively.

These countries means have a respective s.d of 7 million, 6.7 million, 2.5 million, 0.1 million, 0.5 million 0.5 million and 0.7 million. the data set. Therefore, this is an extension to Miller's (2000) paper that had no developing country VSL estimates in its sample.

\section{Results and Discussion}

4.1 Value Transfer and Meta-regressions

As earlier stated, this paper transfers the USEPA's approved estimate of $\$ 6.655$ million as the US VSL for its value transfer calibrations. From our data sources, $Y_{N I G}$ and $Y_{U S}$ are $\$ 1,790$ and $\$ 44,820$ respectively. Incorporating these into equation (i) gives:

$$
V S L_{N I G}=\$ 6,655,000 *\left(\frac{1,790}{44,820}\right)^{e}=\$ 6,655,000 * 0.0399^{e}
$$

Thus, the ratio of Nigeria's GNI per-capita to that of the US in 2006 PPP is approximately 0.04 . Employing an income elasticity of willingness to pay for fatal risk reduction $-e-$ of $1.0,1.5$ and 2.0 gives three calibrations of Nigeria's VSL as presented in Table 4. From the table, it is evident that the large income disparity between Nigeria and the US accentuates the importance of the choice of the income elasticity, $e$, in the value transfer calibration. Employing an elasticity of $1.0,1.5$ and 2.0 respectively gives a $V S L_{N \mid G}$ estimate of approximately $\$ 266,000, \$ 53,000$ and $\$ 11,000$. The large disparity in the estimates provided by these three elasticities no doubt poses a problem on the choice of which estimate is to be employed for health risk analyses. Despite the reliance of a majority of the empirical literature on the choice of 1.0, there has not been any cogent justification for picking this elasticity value. A direct elicitation of this elasticity is likely to provide a value that lies within or outside the range of 1.0 to 2.0. However, this remains unknown until valuation studies are conducted in the country of interest.

Table 5 presents the results of the meta-regressions. The columns labelled 1a to $3 a$ and $1 b$ to $3 b$ contain the results for the double-log and semi-log functional forms, respectively. The first model in each of the functional forms ( $1 \mathrm{a}$ and $1 \mathrm{~b}$ ) is the unrestricted version of the metaregression model in equation (iii). The other models $-2 a, 2 b, 3 a$ and $3 b-$ are the restricted versions of the meta-regression model. The parameter estimates for the double-log specifications present elasticities of VSL with respect to each of the regressors. Based on this 
functional form, the income elasticity of VSL for developing countries ranges from 1.10 to 1.41. The income variable is observed to have a positive and marginally insignificant effect on VSL in the unrestricted model, 1a. However, this variable is significant at the one percent level in the restricted models. Additionally, risk is observed to have a positive and significant effect on VSL; this variable is significant at the five and one percent levels in 1a and 2a respectively.

Further, the $R^{2}$ of the double-log specifications indicates that 56.2 to 62.0 percent of the variation in $\ln (\mathrm{VSL})$ is explained by the regressors and F-statistics indicate that all the explanatory variables are jointly significant in each of the models. However, education, age, developed country binary variable and the interaction term are individually insignificant in the unrestricted model, 1a. Despite being individually insignificant, the negative coefficient of the interaction term suggests that the income elasticity of VSL for developed countries is relatively lower than that for developing countries. As there is a non-zero correlation between the developed country dummy and the interaction variable by construction, an assessment of the importance of including developing countries' VSL estimates in the meta-regression sample on the differential in VSL income elasticity between developed and developing countries requires the use of joint tests in evaluating these variables. Employing an F-test of multiple exclusion restriction indicates that the two variables are jointly insignificant, which may be due to the low number of observations for developing countries in the sample. It is worth noting that the individually insignificant regressors in this model (education, age, the developed country binary variable and the interaction term) are jointly insignificant too.

A similar scenario occurs in the semi-log functional form as in the double-log specifications. Here, income is observed to have a positive and insignificant effect on VSL in the unrestricted model, 1b. Again, this variable becomes significant at the one percent level in the restricted models, $2 \mathrm{~b}$ and $3 \mathrm{~b}$. Risk has a positive and significant effect on VSL in both restricted and unrestricted models. The study type binary variables in the two functional forms (contingent valuation and wage risk) are positive and significant at the one percent level. This sheds light on the importance of estimation technique on VSL differentials. Particularly, a survey of the coefficients of these variables shows that the coefficients of contingent valuations are higher than those of consumer choice studies in all models. Thus, a holistic appraisal of these results shows that our finding moves in tandem with the well documented observation of VSL estimates produced by consumer choice studies being generally lower than those of the contingent valuation method in VSL literature. In a similar vein, the results confirm Kochi et al's (2006) suggestion that wage-risk VSL estimates could be higher than those of contingent valuation.

Additionally, the $R^{2}$ of the semi-log specifications indicates that 53.6 to 61.7 percent of the variation in $\ln (\mathrm{VSL})$ is explained by the regressors and F-statistics show that the explanatory variables are jointly significant in the three models. However, just as in the double-log functional form, education, age, developed country binary variable and the interaction term are individually insignificant in the unrestricted model, 1b. Again, despite being insignificant, the negative coefficient of the interaction term suggests that the income elasticity of VSL for developed countries is relatively lower than that for developing countries. Applying an F-test of multiple exclusion restriction on the developed country dummy and interaction term shows that the two variables are jointly insignificant. ${ }^{18}$ Table 5 also presents the predicted VSL $L_{\text {NIG }}$ provided by each of the three models under the two functional forms. From the double-log specifications, a holistic appraisal of these predictions reveals that Nigeria's VSL ranges from about $\$ 99,000$ to $\$ 1.1$ million, with the lower and upper values of this range given by $3 a$ and $1 \mathrm{a}$ respectively. An analogous prediction by the semi-log functional form yields an estimate of about $\$ 442,000$ to $\$ 2.48$ million, given by $3 \mathrm{~b}$ and $1 \mathrm{~b}$ respectively. A comparison of the variation in VSL predictions by both functional forms shows that the estimates from the latter are relatively higher and have a larger variation compared to those from the former. A further scrutiny of the Nigerian predictions from both functional forms reveals that the predictions for the double-log functional form are closer to the VSL estimates available for developing countries in the meta-regression sample.

More importantly, a further elucidatory analysis on the use of individual t-tests and Ftest of multiple exclusion restriction will lead to the choice of $2 \mathrm{a}$ as the preferred specification in the double-log functional form. For the purpose of comparison we will also consider the same specification (2b) with the semi-log functional form. ${ }^{19}$ To determine which of these functional forms is superior, we employed the Davidson-MacKinnon test for non-nested

It is worth noting that the four individually insignificant variables in this model (education, age, the developed country dummy and interaction term) are jointly significant.

Although the four variables excluded from model $1 \mathrm{~b}$ (in the semi-log functional form) are jointly significant, these variables are all individually insignificant as mentioned above. Since it is somewhat difficult to justify different specifications for the two functional forms or include insignificant variables for the double-log model, we decided to restrict our comparison to models $2 \mathrm{a}$ and $2 \mathrm{~b}$. Note that models $3 \mathrm{a}$ and $3 \mathrm{~b}$ are only used for further analytical illustrations. See ensuing paragraphs for more details. 
models. Conducting this test reveals the following: (a) The test fails to reject the null hypothesis of $2 a$ against the alternative of $2 b$; (b) The test rejects the null hypothesis of $2 b$ in favour of the alternative of $2 a$ at the one percent significance level. As a result, we present model $2 \mathrm{a}$ as our most preferred meta-regression model; thus, giving further justification for the preference of the double-log over the semi-log functional form. ${ }^{20}$ This model predicts VSL $L_{N I G}$ as $\$ 489,000$. This prediction falls within Miller's (2000) prediction of $\$ 40,000$ to $\$ 700,000$ (in 1995 US dollars) for Nigeria's VSL. Additionally, had our prediction only exponentiated predicted $\ln \left(V_{S L_{N I G}}\right)$ and not incorporated the adjustment coefficient, this would have resulted in a Nigerian VSL estimation of about $\$ 361,000$. Obviously, there is a considerable difference in predictions obtained with and without the adjustment. This difference indicates the importance of incorporating this retransformation in predictions employing regression functions with logged dependent variables. ${ }^{21}$

Next, a comparison of the VSL prediction from the most preferred meta-regression specification and the multiple calibrations provided by the use of three income elasticities by the value transfer method indicates that the latter benefit transfer technique leads to lower VSL estimates than the former. ${ }^{22}$ Also, some analysts would argue in favour of the use of the US average VSL in the sample for value transfer estimations as opposed to using an individual VSL estimate, such as the estimate approved by USEPA. This does not affect the analysis as the use of the US mean VSL estimate of $\$ 7.66$ million would lead to a Nigerian calibration of about

Employing the same test in comparing the two unrestricted models, $1 \mathrm{a}$ against $1 \mathrm{~b}$, leads to a nonrejection of either model. The same result is obtained comparing the restricted model $2 \mathrm{a}$ against the unrestricted model $1 \mathrm{~b}$. However, employing the adjusted $\mathrm{R}^{2}$ of choosing between non-nested models leads to a rejection of $1 \mathrm{~b}$ in favour of both 1a and 2a, since the former has a lower adjusted $\mathrm{R}^{2}$ than the latter two. See Wooldridge (2008) for details on the use of adjusted $R^{2}$ for testing non-nested models.

The use of the Smearing Factor approach may be biased in the presence of heteroscedasticity (Manning and Mullahy, 2001). However, we conducted both the White and Breusch-Pagan/Cook-Weisberg tests for hetersocedasticity for all of the specifications in Table 5. The two tests fail to reject the null hypothesis of homoscedasticity in all models. Thus, these results suggest that heteroscedasticity may not be a problem in our models and the retransformations of the log predicted VSL undertaken in the paper does not seem to be biased based on the use of the Smearing Factor approach.

However, just as initially noted, the value transfer calibrations are highly dependent on the elasticity employed. Particularly, the elasticities provided by our meta-regression results raise doubts on the conventional practice of using an income elasticity of unity for developing countries. With precise reference to Robinson and Hammitt's (2009) suggestion about using an elasticity of 1.0 to 2.0 for developing countries, our results indicate that the lower tail of this range is not necessarily equal to one. In fact, our results suggest that the inclusion of more developing countries in the sample is likely to move this lower bound elasticity away from 1.0, thereby making it more elastic. Thus, it might be worth setting the lower bound of the value transfer (elasticity) range with the statistically estimated elasticity of 1.30 given by the most preferred meta-regression specification. It is worth nothing that this elasticity estimate of 1.30 is statistically different from one. However, incorporating this in our analysis does not change the major conclusions arrived at by comparing the two benefit transfer methods investigated, but it might be an important point to explore in similar applications.
$\$ 306,000, \$ 61,000$ and $\$ 12,000$ given by an elasticity of $1.0,1.5$ and 2.0 respectively. Thus, our conclusion of value transfer calibrations leading to lower VSL estimates than the metaregression predictions remains unchanged.

Finally, the meta-regression models restricting the vector of explanatory variables to only income and study type dummies ( $3 a$ and $3 b$ ) provide the lowest VSL predictions in the two functional forms explored. These estimates indicate the likelihood of underestimating the VSL by the meta-regression method too when the analysis concentrates on income and neglects fatal risk and other important factors affecting the VSL. Thus, the weight of evidence in comparing the two benefit transfer techniques leads to the conclusion that the value transfer method is likely to lead to an underestimation of the VSL for developing countries as the method neglects important determinants of VSL in its benefit transfer application, especially mortality risk. Consequently, this paper presents $\$ 489,000$ as its most preferred VSL estimate for Nigeria.

4.2 Health and Economic Cost

We next use equation (iv) to estimate the mortality costs of $\mathrm{PM}_{10}$ in Nigeria. Based on data provided by the World Bank (WDI, September 2010 edition), Nigeria's 2006 average PM10 concentration and population are $44.99 \mu \mathrm{g} / \mathrm{m}^{3}$ and $142,721,843$ people respectively. Its crude mortality rate in 2006 was 17 per 1000 people (World Bank, 2010) or 1.7 percent. From the DRFs transferred from the epidemiological literature, our lower and upper estimates of mortality DRCs are 0.096 and 0.13 percent (equal to a factor of 0.00096 and 0.0013 , respectively). We denote the former $b_{\text {lowerDRC,mortality }}$ and the latter $b_{\text {upperDRC,mortality. The use of }}$ the WHO $\mathrm{PM}_{10}$ annual air quality guideline of $20 \mu \mathrm{g} / \mathrm{m}^{3}$ gives $d P M_{10}$ as $24.99 \mu \mathrm{g} / \mathrm{m}^{3}$. Incorporating these into equation (iv) gives the following transformation:

$$
H_{\text {mortality, } P M_{10}}=b_{i} * 0.017 * 142,721,843 * d P M_{10}
$$

where $b_{i}=b_{\text {lowerDRC, mortality }}$ and $b_{\text {upperDRC, mortality. }}$

The results of these estimations are provided in Table 6. The table provides estimates of mortality cases emanating from particulate pollution in Nigeria. If particulate pollution in 
Nigeria was mitigated to the WHO standard, this would have led to a decrease in premature mortality by about 58,200 to 78,800 people in 2006 . Since Nigeria's crude mortality rate and population estimates are respectively 1.7 percent and 142.7 million people, these mortality estimates are therefore approximately 2.2 percent and 3.3 percent of total (implied) deaths for $2006-2.4$ million people. ${ }^{23}$ Hence, these results imply significant benefits in the form of mortality reductions to be expected from the abatement of particulate pollution.

Table 7 presents the mortality related welfare losses resulting from particulate pollution in Nigeria. These results imply a mortality related welfare loss of $\$ 28.46$ billion to $\$ 38.54$ billion given by the lower and upper coefficients of the $\mathrm{PM}_{10} \mathrm{DRFs}$ respectively. This loss translates to 19.4 to 26.3 percent of the nation's 2006 GDP. ${ }^{24}$ Put more succinctly, had the nation mitigated its particulate pollution to the WHO standards, it could have avoided at least 58,207 premature deaths and recorded an avoided mortality related welfare loss of $\$ 28.46$ billion in 2006

\section{Concluding Remarks}

Assessment of the mortality and economic costs of air pollution amplifies the relevance of incorporating environmental management into economic policies. The unavailability of primary data from policy site poses an obstacle to making informed decisions in analysing the potential welfare gains of mitigating air pollution. The value of statistical life is an essential parameter in ascribing monetary values to the mortality costs of air pollution. This lack of information has left researchers with the choice of employing one of two major benefit transfer techniques - value transfer or meta-regression - in their health risk analyses. We set forth to determine which of the two transfer methods better suits developing countries. Using Nigeria as a case study, a comparison of the two methods reveals the following: (a) the value transfer method does not incorporate many characteristics that vary from the study site to policy site; (b) the value transfer technique is likely to underestimate the value of statistical life for very low-income countries as it assumes that income is the only factor accounting for

This (implied) death estimate is not too far from the country's 2004 recorded deaths of 2.2 million people (WHO, 2009).

Nigeria's 2006 GDP at current dollars is \$146.88 billion (World Bank - WDI, September 2010 edition). differences in value of statistical life between study site and policy site; (c) the value transfer application leaves much more to the judgment of the analyst, which leaves open the possibility of manipulation. Thus, we conclude that the meta-regression approach is likely to provide more accurate VSL predictions for very low-income countries. This method provides a prediction of $\$ 489,000$ for Nigeria's value of statistical life. It is, however, worth noting that this finding may be sensitive to the data employed in the regressions because there is a low representation of developing countries in the sample. Hence, the paper could be improved by incorporating more developing country money-risk trade-off valuations, in anticipation of a rise in the number of these valuation studies in the future.

Employing the most preferred VSL estimate, $\$ 489,000$, this paper provides the first approximation of the mortality related benefits associated with improving air quality in Nigeria. We found that if Nigeria had mitigated its 2006 particulate pollution to the WHO standards, this action would have prevented at least 58,000 premature deaths and recorded an avoided mortality related welfare loss of about $\$ 28$ billion. This amount translates to 19 percent of Nigeria's GDP for that year. As a result, the nation bears massive human capital and welfare losses through its particulate pollution. While it is common knowledge that death is inevitable, it is also important for people to know that they can live healthier and more productive lives, thereby prolonging their life span. Thus, the mitigation of air pollution can mean significant benefits for the nation; in terms of a healthier and more productive labour force. Given that the costs of other air pollutants are not considered, the estimate presented by our paper is therefore a conservative one. Consequently, the potential benefits of mitigation may exceed those presented in this paper.

This study is limited by its choice of explanatory variables employed in the metaregression analysis, especially the variables measuring information on different kinds of mortality risks, education and life expectancy at birth. The results may have been improved by using a variable that only concentrates on information regarding the fatal dangers of air pollution and not mortal risks in general, given that the study is on air pollution. Also, the education variable might be a weak representation of individuals' awareness of these fatal dangers. Similarly, the life expectancy variable might be difficult to justify given the contention on the effect of age on individuals' risk avoidance preferences. However, the inclusion of these variables (education and life expectancy) in our models sheds light on the fact that in addition 
to income and risk, there could be other important variables explaining individuals' risk avoidance preferences. Future studies could delve into improved ways of measuring these variables or explore other variables that could be significant determinants of money-risk tradeoffs.

Another limitation of this and similar studies hinges on the transferability of dose response functions which are mainly estimated from the developed world and transferred to developing nations. As a result of the large differences in climatic, demographic and welfare conditions between the developed and developing world, there is uncertainty whether or not the transferability of these estimates leads to an overestimation or underestimation of the mortality costs of particulate pollution in Nigeria. Nevertheless, currently, the assumption of transferable dose response functions is indispensable in health risk analyses for Nigeria and a majority of other developing nations due to the unavailability of local estimates. However, the need for more credible health risk analyses should influence these countries to make conscious efforts in developing their own dose response functions. This could be achieved by working in collaboration with international organisations such as the World Bank and World Health Organisation or with developed nations such as the United States, United Kingdom, Canada and Sweden among others who are experienced in conducting health risk research.

Table $1 \mathrm{PM}_{10}$ Dose Response Coefficients for Mortality Health Effect ( $\mathrm{b}_{\text {mortality,PM10 }}$ )

\begin{tabular}{ccc}
\hline Lower Coefficient & Central Coefficient & Upper Coefficient \\
\hline 0.062 & 0.096 & 0.13 \\
\hline
\end{tabular}

\begin{tabular}{|c|c|c|c|c|c|}
\hline $\begin{array}{c}\text { countRY } \\
\text { Study }\end{array}$ & VSL (2006 US\$) & $\begin{array}{l}\text { GN PER-CAPITA, in } \\
\$ 2006 \text { PPP (gnipc) }\end{array}$ & $\begin{array}{l}\text { CRUDE MORTALITY } \\
\text { RATE (riskc) }\end{array}$ & 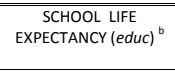 & $\begin{array}{c}\text { LIFE } \\
\text { EXPEXTANCE AT } \\
\text { BIRTH }(a g e)^{3} \\
\end{array}$ \\
\hline $\begin{array}{l}\text { AUUSRRAAlA } \\
\text { Kneisner \& Leeth (1991) } \\
\text { Miller, Mulvey \& Norris (1997) }\end{array}$ & $\begin{array}{l}4,917,073 \\
17,795,122\end{array}$ & $\begin{array}{l}33,030 \\
33,030\end{array}$ & $\begin{array}{l}7 \\
7\end{array}$ & $\begin{array}{l}21 \\
21\end{array}$ & $\begin{array}{l}81.04 \\
81.04\end{array}$ \\
\hline $\begin{array}{l}\text { AUSTRIA } \\
\text { Weiss, Maier \& Gerking (1986) } \\
\text { Maier et al. (1989) }\end{array}$ & $\begin{array}{l}5,944,819 \\
4,787,339\end{array}$ & $\begin{array}{l}35,690 \\
35,690\end{array}$ & $\begin{array}{l}9 \\
9\end{array}$ & $\begin{array}{l}15 \\
15\end{array}$ & $\begin{array}{l}79.9 \\
79.9\end{array}$ \\
\hline $\begin{array}{l}\text { CANADA } \\
\text { Cousineau (19992) } \\
\text { Cousineau, Lacroix \& Girard (1992) } \\
\text { Lanoie, Pedro \& Latour (1995) } \\
\text { Martinello \& Meng (1992) } \\
\text { Meng (1989) } \\
\text { Meng \& Smith (1990) } \\
\text { Mens \& Smith (1999) } \\
\text { Vodden et al. (1993) }\end{array}$ & $\begin{array}{l}5,399,765 \\
5,385,366 \\
24,175,610 \\
5,268,293 \\
5,034,446 \\
9,834,146 \\
6,087,705 \\
4,251,591\end{array}$ & $\begin{array}{l}36,470 \\
36,470 \\
36,470 \\
36,470 \\
36,470 \\
36,470 \\
36,470 \\
36,470\end{array}$ & $\begin{array}{l}7 \\
7 \\
7 \\
7 \\
7 \\
7 \\
7 \\
7\end{array}$ & $\begin{array}{l}16 \\
16 \\
16 \\
16 \\
16 \\
16 \\
16 \\
16\end{array}$ & $\begin{array}{l}88.064 \\
88.64 \\
88.64 \\
80.64 \\
88.64 \\
80.64 \\
80.64 \\
80.64\end{array}$ \\
\hline $\begin{array}{l}\text { CHINA } \\
\text { Guo \& Hammitt (2009) } \\
\text { Wang \& Mullahy (2006) }\end{array}$ & $\begin{array}{l}81,951 \\
43,288\end{array}$ & $\begin{array}{l}4,790 \\
4,790\end{array}$ & $\begin{array}{l}7 \\
7\end{array}$ & $\begin{array}{l}11 \\
11\end{array}$ & $\begin{array}{l}72.76 \\
72.76\end{array}$ \\
\hline $\begin{array}{l}\text { CHILE } \\
\text { Ortuar, Cifuentes \& Williams (2000) } \\
\text { Ortuzar, Cifuentes \& Williams (2000) }\end{array}$ & $\begin{array}{l}308,571 \\
630,454\end{array}$ & $\begin{array}{l}\begin{array}{l}11,380 \\
11,380\end{array} \\
\end{array}$ & $\begin{array}{l}5 \\
5\end{array}$ & $\begin{array}{l}15 \\
15\end{array}$ & $\begin{array}{l}78.39 \\
78.39\end{array}$ \\
\hline $\begin{array}{l}\text { DENMARK } \\
\text { Kidholm (1995) }\end{array}$ & $14,158,299$ & 36,410 & 10 & 17 & 78.35 \\
\hline $\begin{array}{l}\text { FRANCE } \\
\text { Desaigues \& Rabl (1995) }\end{array}$ & $14,717,858$ & 32,170 & 8 & 16 & 80.81 \\
\hline
\end{tabular}


Environmental \& Resource Economics accepted

\begin{tabular}{|c|c|c|c|c|c|}
\hline $\begin{array}{l}\text { INDIA } \\
\text { Bhattacharya, Alberini, and Cropper (2007) } \\
\text { Mahdeswaran (2007) } \\
\text { Madheswaran (2007) }\end{array}$ & $\begin{array}{l}154,839 \\
372,778 \\
357,559\end{array}$ & $\begin{array}{l}2,550 \\
2,550 \\
2,550\end{array}$ & $\begin{array}{l}8 \\
8 \\
8\end{array}$ & $\begin{array}{l}10 \\
10 \\
10\end{array}$ & $\begin{array}{l}63.08 \\
63.08 \\
63.08\end{array}$ \\
\hline $\begin{array}{l}\text { JAPAN } \\
\text { Kneisner \& Leeth (1991) }\end{array}$ & $11,356,098$ & 32,720 & 9 & 15 & 82.32 \\
\hline $\begin{array}{l}\text { HONG KONG } \\
\text { Siebert \& Wei (1998) }\end{array}$ & $1,990,244$ & 39,910 & 6 & 14 & 82.38 \\
\hline $\begin{array}{l}\text { MALLAYSIA } \\
\text { Mellhuish, Ross, Goodge, et al. (2005) }\end{array}$ & 594,939 & 12,240 & 4 & 12 & 73.94 \\
\hline $\begin{array}{l}\text { MEXICO } \\
\text { Hammitt \& Ibarraran (2006) }\end{array}$ & 313,774 & 13,550 & 5 & 14 & 74.47 \\
\hline $\begin{array}{l}\text { NEW ZEALAND } \\
\text { Miller \& Guria (1991) } \\
\text { Miller \& Guria (1991) } \\
\text { Guria et al. (1999) }\end{array}$ & $\begin{array}{l}1,816,252 \\
1,155,937 \\
2,777,953\end{array}$ & $\begin{array}{l}24,760 \\
24,760 \\
24,760\end{array}$ & $\begin{array}{l}7 \\
7 \\
7\end{array}$ & $\begin{array}{l}19 \\
19 \\
19\end{array}$ & $\begin{array}{l}80.05 \\
80.05 \\
80.05\end{array}$ \\
\hline $\begin{array}{l}\text { POLAND } \\
\text { Giergicny (2008) }\end{array}$ & $2,720,982$ & 14,640 & 10 & 15 & 75.18 \\
\hline $\begin{array}{l}\text { SoUTH KOREA } \\
\text { Kim (1985) } \\
\text { Kim \& Fishback (1993) } \\
\text { Kim \& Fishback (1999) }\end{array}$ & $\begin{array}{l}1,731,591 \\
936,585 \\
896,882\end{array}$ & $\begin{array}{l}24,340 \\
24,340 \\
24,340\end{array}$ & $\begin{array}{l}5 \\
5 \\
5\end{array}$ & $\begin{array}{l}17 \\
17 \\
17\end{array}$ & $\begin{array}{l}78.97 \\
78.97 \\
78.97\end{array}$ \\
\hline $\begin{array}{l}\text { SWEDEN } \\
\text { Johannesson et al. (1997) } \\
\text { Persson \& Caldervall (1991) } \\
\text { Persson ta tal. (19995) } \\
\text { Sodedrovist (1994) }\end{array}$ & $\begin{array}{l}6,864,189 \\
2,314,961 \\
6,091,654 \\
1,956,472 \\
\end{array}$ & $\begin{array}{r}36,360 \\
36,360 \\
36,360 \\
36,360\end{array}$ & $\begin{array}{l}10 \\
10 \\
10 \\
10\end{array}$ & $\begin{array}{l}16 \\
16 \\
16 \\
16\end{array}$ & $\begin{array}{l}80.87 \\
80.87 \\
80.87 \\
80.87\end{array}$ \\
\hline
\end{tabular}

Environmental \& Resource Economics accepted

\begin{tabular}{|c|c|c|c|c|c|}
\hline $\begin{array}{l}\text { SWITZERLAND } \\
\text { Schwab-Christe (1995) } \\
\text { Barazzini \& Luzzi (2001) }\end{array}$ & $\begin{array}{l}\begin{array}{l}15,695,433 \\
8,721,951\end{array} \\
\end{array}$ & $\begin{array}{l}42,870 \\
42,870\end{array}$ & $\begin{array}{l}8 \\
8\end{array}$ & $\begin{array}{l}15 \\
15\end{array}$ & $\begin{array}{l}81.66 \\
81.66\end{array}$ \\
\hline $\begin{array}{l}\text { THALLLAND } \\
\text { Vassanadumrongdee \& Matsouka (2005) }\end{array}$ & & & & & \\
\hline 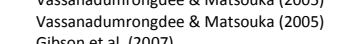 & $\begin{array}{l}1,651,565 \\
1,272,205\end{array}$ & $\begin{array}{l}0,970 \\
6,970\end{array}$ & 9 & 12 & $\begin{array}{l}68.55 \\
68.55 \\
68.55\end{array}$ \\
\hline & & & & & \\
\hline $\begin{array}{l}\text { UNITED KINGGDM } \\
\text { Arabsheibani \& Marin (2000) }\end{array}$ & & & & & \\
\hline $\begin{array}{l}\text { Arabsheibanil \& Marin (2000) } \\
\text { Ghosh et al. (1975) }\end{array}$ & $\begin{array}{l}23,29,561 \\
2254,110\end{array}$ & $\begin{array}{l}35,180 \\
35,180\end{array}$ & 9 & $\begin{array}{l}16 \\
16\end{array}$ & $\begin{array}{l}79.45 \\
79.45\end{array}$ \\
\hline $\begin{array}{l}\text { Goosh et al. (19/5) } \\
\text { Jones-Lee et al. (1983) }\end{array}$ & $\begin{array}{l}2,2,24,110 \\
6,272,882\end{array}$ & $\begin{array}{l}35,180 \\
35,180\end{array}-20$ & ${ }_{9}^{9}$ & ${ }_{16}^{16}$ & $\begin{array}{l}79.45 \\
79.45\end{array}$ \\
\hline Jones-lee et al. (1995) & $3,694,677$ & 35,180 & 9 & 16 & 79.45 \\
\hline Maclean (1979) & $3,334,866$ & 35,180 & 9 & 16 & 79.45 \\
\hline Marin \& Psacharapoulos (1982) & $5,278,110$ & 35,180 & 9 & 16 & 79.45 \\
\hline Melinek (1974) & $1,927,370$ & $\begin{array}{r}35,180 \\
35,180\end{array}$ & 9 & 16 & 79.45 \\
\hline $\begin{array}{l}\text { Melinek (1974) } \\
\text { Siebert \& Wei (1994) }\end{array}$ & $\begin{array}{r}2,1,27,118 \\
12,234,146\end{array}$ & $\begin{array}{l}35,180 \\
35,180\end{array}$ & ${ }_{9}^{9}$ & $\begin{array}{l}16 \\
16\end{array}$ & $\begin{array}{l}79.45 \\
79.45\end{array}$ \\
\hline UNITED STATES & & & & & \\
\hline $\begin{array}{l}\text { UIIfED SAAES } \\
\text { Smith (1974) }\end{array}$ & $10,770,732$ & 44,820 & 8 & 16 & 77.99 \\
\hline Thaler \& Ronson (1975) & $1,170,732$ & 44,820 & 8 & 16 & 77.99 \\
\hline $\begin{array}{l}\text { SMith (1976) } \\
\text { Viscusil (19789 1979) }\end{array}$ & $6,907,317$ & $\begin{array}{l}44,820 \\
44,820\end{array}$ & 8 & ${ }_{16}^{16}$ & 77.99 \\
\hline 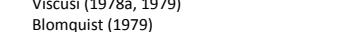 & $\begin{array}{l}6,2,24,878 \\
1,170,732\end{array}$ & $\begin{array}{l}44,820 \\
44,820\end{array}$ & $\begin{array}{l}8 \\
8\end{array}$ & $\begin{array}{l}16 \\
16\end{array}$ & 77.99 \\
\hline $\begin{array}{l}\text { Brown (1980) } \\
\text { Brom }\end{array}$ & $2,224,390$ & $\begin{array}{l}44,820 \\
44,820\end{array}$ & 8 & 16 & 77.99 \\
\hline Dardis (1980) & 901,463 & 44,820 & 8 & 16 & 77.99 \\
\hline Portney (1981) & $1,205,854$ & 44,820 & 8 & 16 & 77.99 \\
\hline Viscusi (1981) & $9,717,073$ & 44,820 & 8 & 16 & 77.99 \\
\hline 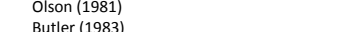 & $\begin{array}{l}7,843,902 \\
1521,951\end{array}$ & 44,820 & 8 & $\begin{array}{l}16 \\
16\end{array}$ & 77.99 \\
\hline $\begin{array}{l}\text { Butler (1983) } \\
\text { Low \& Mcheters (1983) }\end{array}$ & $\begin{array}{l}1,521,951 \\
1.639024\end{array}$ & 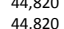 & 8 & $\begin{array}{l}16 \\
16\end{array}$ & 77.99 \\
\hline Leigh \& Folsom (1984) & $\begin{array}{l}1,0699,024 \\
13,697,561\end{array}$ & $\begin{array}{l}44,820 \\
44,820\end{array}$ & 8 & 16 & 77.99 \\
\hline Smith \& Gilbert (1984, 1985) & 1,053,659 & 44,820 & 8 & 16 & 77.99 \\
\hline
\end{tabular}




\section{Environmental \& Resource Economics accepted}

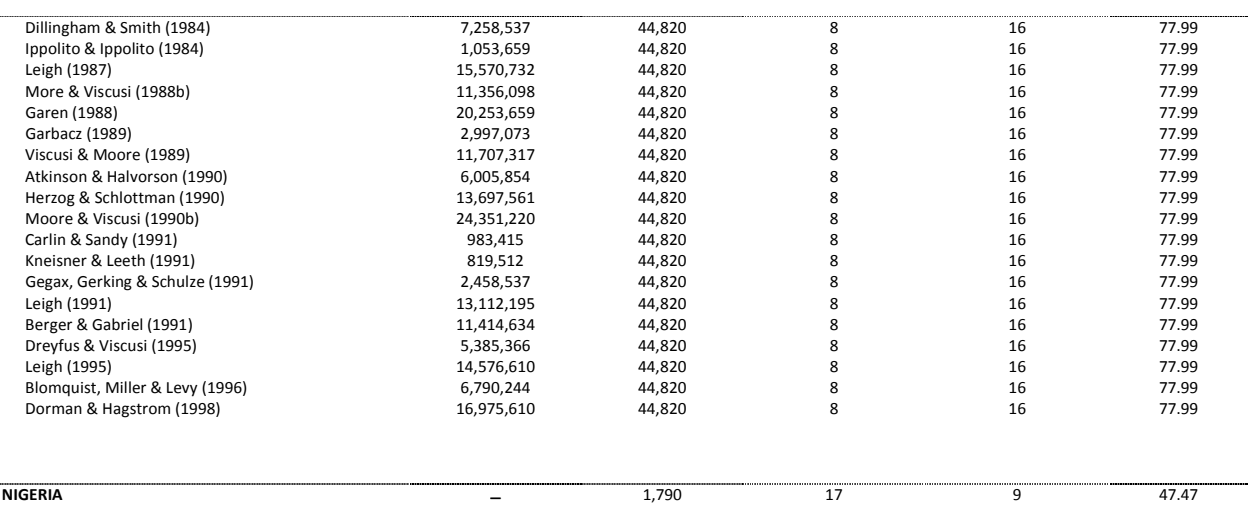

Data on GNI per-capita based on purchasing power parity are obtained from the World Bank's World Development Indicators (Sept. 2010 Edition) available online at http://econ worldbank. org/Data on life expectancy(LE) at birth are also obtained from the same source.

Data on school life expectancy are obtained from United Nations Statistics Division (2010) available online at http://unstats.un.org/ unssd/demegraphic//roducts/socind//education. htm. The data provided by this source are not for the year 2006 alone but also for other close 2006 . Data on crude mortality rate (CMR) are obtained from the World Bank (2010) available at http://data.worldbank.org/indicator/SP. DYN.CDRT.IN/countries

\section{Environmental \& Resource Economics accepted}

the US is 8 per 1000 people - or $0.8 \%$ - while it is only 5 per 1000 people - or $0.5 \%$ - in Chile. This is due to the fact that a country's CMR depends on both its age speciffe mortally rate and age dist - o $08 \%$ - Wher developed countries record a higher CMR than some of their developing counterparts despite life expectancy being higher in the former than the latter.

Notes on Value of Statistical Life Estimates in Table 2

1. For VSLL reported as a range of values in the original studies, this table reports the mid-point/mean of the range.

2. Viscusi and Aldy's (2003) paper presents 41 US and 23 non-US VSL estimates (in US 2000 dollars). Of these studies, this paper only employs 33 US and 16 non-US studies in its analysis due to the following reasons. First, Sandy and Elliot's (1996) study reports a mean UK VSL of $\$ 43.7$ million. Similarly, Shanmugam (2001) reports a mean Indian VSL of $\$ 4.8$ million. Compared to other estimates for these countries, these papers' estimates are too high. produces the same US VSL estimate, $\$ 20.8$ million, as Moore and Viscusi (1990b). Third, the other studies were dropped becouse they provided more than one VSL estimate and at the same time, these were not in a range of values. Consequently, there was neither a clear cut nor an objective way of taking the mean of these estimates. These studies are: Arnold and Nicholas (1983): Dorsey and Walzer (1983): Dillingham (1985): Moore and Viscusi (1988a); Lott and Manning (2000); Gayer, Hamilton and Viscusi (2000); Jenkins, Owens and Wiggins (2001); Shanmugam (1996/1997 and 2000); and Sandy et al. (2001). Fourth, due to the unavailability of credible data for Taiwan's GNI per-capita, crude mortality rate, school life expectancy and life expectancy at birth (recall these variables serve as the regressors in the meta-regression models); four Taiwanese studies - two each from Viscusi and (2000) for a list of reference on studies transterred fron

3. From Viscusi and Aldy (2003), this table reports the mean of the VSL for US residents and immigrants estimated in Berger and Gabriel (1991).

4. 21 non US VSL estimates were transferred from Miller (2000). However, 7 of these 21 studies also appear in Viscusi and Aldy (2003). These are the Meng, 1989; Meng and Smith, 1990); Japan (Kneisner and Leeth, 1991); and UK (Marin and Psacharapoulos, 1982).

5. 13 other non-US VSL estimates, mainly for developing countries, were obtained through a literature search. These are the estimates for: China (Guo and Hammitt, 2009: Wang and Mullahy, 2006); Chile (Ortuzar, Cifuentes and Williams, 2000 and 2000); India (Bhattacharya, Alberini and Cropper, 2007: 
Table 3 Summary of Value of Statistical Life Estimates by Country of Origin

\begin{tabular}{cccc}
\hline Country & Number of Values & Mean Value & Standard Deviation \\
\hline Australia & 2 & $11,356,098$ & $9,106,156$ \\
Austria & 2 & $5,366,079$ & 818,462 \\
Canada & 8 & $8,179,265$ & $6,679,756$ \\
China & 2 & 62,620 & 27,339 \\
Chile & 2 & 469,513 & 227,606 \\
Denmark & 1 & $14,158,299$ & - \\
France & 1 & $14,717,858$ & - \\
India & 3 & 295,059 & 121,672 \\
Japan & 1 & $11,356,098$ & - \\
Hong Kong & 1 & $1,990,244$ & - \\
Malaysia & 1 & 594,939 & - \\
Mexico & 1 & 313,774 & - \\
New Zealand & 3 & $2,150,047$ & 544,144 \\
Poland & 1 & $2,720,982$ & - \\
South Korea & 3 & $1,188,353$ & 470,877 \\
Sweden & 4 & $4,306,819$ & $2,530,969$ \\
Switzerland & 2 & $12,208,692$ & $4,930,996$ \\
Thailand & 3 & $1,123,365$ & 744,184 \\
United Kingdom & 9 & $6,713,427$ & $7,001,068$ \\
United States & 33 & $7,660,518$ & $6,396,053$ \\
Total & & $6,203,952$ & \\
\hline
\end{tabular}

Table 4 Nigeria's Value Transfer VSL Calibrations

\begin{tabular}{cccc}
\hline \multicolumn{4}{c}{ Income elasticity for fatal risk reduction } \\
\hline 1.0 & 1.5 & 2.0 \\
$V S L_{N I G}$ & $\$ 265,784$ & $\$ 53,115$ & $\$ 10,615$ \\
\hline \hline
\end{tabular}


Table 5 Summary of OLS Regression Results for Meta-regression Analysis and Predicted Value of Statistical Life for Nigeria Based on Estimated Coefficients (Robust Standard Errors in Parenthesis)

Dep Variable: $\ln (V S L)$

number of observations $=83$

\begin{tabular}{|c|c|c|c|}
\hline Explanatory Variables & $1 \mathrm{a}$ & $2 a$ & $3 a$ \\
\hline $\ln ($ gnipc) & $1.101(0.687)$ & $1.295 *(0.154)$ & $1.409 *(0.179)$ \\
\hline $\ln (r i s k)$ & $1.642 * *(0.670)$ & $1.735 *(0.399)$ & - \\
\hline $\ln (e d u c)$ & $1.622(1.409)$ & - & - \\
\hline $\ln (a g e)$ & $-3.060(5.193)$ & - & - \\
\hline$C V$ & $0.997 *(0.323)$ & $0.920 *(0.292)$ & $0.987^{*}(0.296)$ \\
\hline$W R$ & $1.189 *(0.271)$ & $1.167^{*}(0.262)$ & $1.085 *(0.259)$ \\
\hline$d$ & $0.910(7.575)$ & - & - \\
\hline $\ln (g n i p c d)$ & $-0.052(0.774)$ & - & - \\
\hline intercept & $7.907(17.440)$ & $-2.819(1.730)$ & $-0.408(1.905)$ \\
\hline$R^{2}$ & 0.620 & 0.609 & 0.562 \\
\hline F-stat & 16.57 & 28.40 & 25.63 \\
\hline Adjustment Coefficient & 1.346 & 1.352 & 1.406 \\
\hline Predicted In $\left(V S L_{N I G}\right)$ & 13.619 & 12.798 & 11.165 \\
\hline \multirow{2}{*}{ Adjusted VSL $L_{N \mid G}$} & $\$ 1,105,864$ & $\$ 488,740$ & $\$ 99,285$ \\
\hline & $1 \mathrm{~b}$ & $2 b$ & $3 b$ \\
\hline gnipc & $0.0001511(0.0001047)$ & $0.0000722^{*}(9.65 \mathrm{e}-06)$ & $0.0000788^{*}(9.40 \mathrm{e}-06)$ \\
\hline risk & $0.255 *(0.095)$ & $0.168 *(0.063)$ & - \\
\hline educ & $0.110(0.082)$ & - & - \\
\hline age & $-0.014(0.063)$ & - & - \\
\hline$C V$ & $0.952^{*}(0.328)$ & $1.111 *(0.329)$ & $1.242^{*}(0.328)$ \\
\hline$W R$ & $1.178 *(0.270)$ & $1.178^{*}(0.291)$ & $1.138^{*}(0.292)$ \\
\hline$d$ & $1.974(1.549)$ & - & - \\
\hline gnipcd & $-0.0001183(0.0001083)$ & - & - \\
\hline intercept & $8.462^{* *}(3.889)$ & $10.203^{*}(0.609)$ & $11.290 *(0.468)$ \\
\hline$R^{2}$ & 0.617 & 0.556 & 0.536 \\
\hline F-stat & 16.39 & 22.25 & 25.09 \\
\hline Adjustment Coefficient & 1.355 & 1.406 & 1.435 \\
\hline Predicted $\ln \left(V S L_{N I G}\right)$ & 14.420 & 14.322 & 12.638 \\
\hline Adjusted VSL $L_{N I G}$ & $\$ 2,480,080$ & $\$ 2,333,194$ & $\$ 442,044$ \\
\hline
\end{tabular}

Table 6 Mortality Costs of $\mathrm{PM}_{10}$ Pollution in Nigeria $\mathrm{dPM}_{10, \text { wHO target }}$

\begin{tabular}{lc}
\hline $\mathrm{b}_{\text {lowerDRC, mortality }}$ & $\mathrm{b}_{\text {upperDRC, mortality }}$ \\
\hline 58,207 & 78,822 \\
\hline
\end{tabular}

Table 7 Economic Costs of $\mathrm{PM}_{10}$ Pollution in Nigeria

\begin{tabular}{lcc}
\hline & \multicolumn{2}{c}{$d P M_{10, \text { WHO target }}$} \\
\cline { 2 - 3 } & $b_{\text {lowerDRC, mortality }}$ & $b_{\text {upperDRC, mortality }}$ \\
\cline { 2 - 3 } Economic Cost (billions of US \$) & 28.46 & 38.54 \\
Economic cost as a percentage of GDP & 19.4 & 26.3 \\
\hline
\end{tabular}

\section{References}

Akbostanci E, Turuk-Asik S, Tunc, G (2009) The Relationship between Income and Environment in Turkey: Is there an Environmental Kuznets Curve? Energy Policy 37(3): 861-867

Bates DV (1980) The Health Effects of Air Pollution. Journal of Respiratory Disease 1: 29-37

Bellavance F, Dionne G, Lebeau M (2009) The Value of Statistical Life: A Meta-analysis with Mixed Effects Regression Model. Journal of Health Economics 28(2): 444-464

Bhattacharya S, Alberini A, Cropper M (2007) The Value of Mortality Risk Reductions in Delhi, India Journal of Risk and Uncertainty 34(1): 21-47

Bowland B, Beghin J (2001) Robust Estimates of Value of a Statistical Life for Developing Countries. Journal of Policy Modelling 23(4): 385-396

Boyle K, Kuminoff N, Parmeter C, Pope J (2009) Necessary Conditions for Valid Benefit Transfers. American Journal of Agricultural Economics 91(5): 1328-1334

(2010) The Benefit-Transfer Challenges. Annual Review of Resource Economics 2(1): 161-182 
Chestnut G, Ostro B, Vichit-Vadakan N (1997) Transferability of Air Pollution Control Health Benefits Estimates from the United States to Developing Countries: Evidence from the Bangkok Study. American Journal of Agricultural Economics 79(5): 1630-1635

Clayton GD (1978) Air Pollution. In: Clayton GD (1991) Patty's Industrial Hygiene and Toxicology: Vol 1, General Principles, 3edn. John Wiley, New York

Cropper M, Simon, N (1996) Valuing the Health Effects of Air Pollution. Available via http://info.worldbank.org/etools/docs/library/36659/valuingthehealth.pdf

Daniels M, Dominici F, Samet J, Zeger S (2000) Estimating Particulate Matter Mortality Dose Response Curves and Threshold Levels: An Analysis of Daily Time-Series for the 20 Largest US Cities. American Journal of Epidemiology 152(5): 397-406

de Blaeij A, Florax J, Rietveld P, Verhoef E (2003) The Value of Statistical Life in Road Safety: A Metaanalysis. Accident Analysis and Prevention 35(6):973-986

Dickie M, List J (2006) Economic Valuation of Health for Environmental Policy: Comparing Alternative Approaches. Introduction and Overview. Environmental and Resource Economics 34(3): 339-346

Dixon J, Scura L, Carpenter R, Sherman P (1994) Economic Analysis of Environmental Impacts, 2 edn. Earthscan, London

Dominici F, McDermott A, Zeger S, Samet J (2003) Airborne Particulate Matter and Mortality: Timescale Effects in Four US Cities. American Journal of Epidemiology 157(12): 1055-1065

Garbacz C (1989) Smoke Detector Effectiveness and the Value of Saving a Life. Economic Letters 31(3): $281-286$

Gibson J, Barns S, Cameron M, Lim S, Scrimgeour F, Tressler J (2007) The Value of Statistical Life and the Economics of Landmine Clearance in Developing Countries. World Development 35(3): 512-531

Giergiczny M (2008) Value of a Statistical Life - The Case of Poland. Environmental and Resource Economics 41(2): 209-221

Glover D (2002) Valuing the Health Impacts of Air Pollution: Notes and Suggested Readings. Available via http://www.idrc.ca/es/ev-8314-201-1-DO_TOPIC.html

Guo X, Hammitt J (2009) Compensating Wage Differentials with Unemployment: Evidence from China. Environmental and Resource Economics 42(2): 187-209

Hainoun A, Almoustafa A, Seif Aldin M (2010) Estimating the Health Damage Costs of Syrian Electricity Generation System Using Impact Pathway Approach. Energy 35(2): 628-638

Hammitt JK (2000) Valuing Mortality Risk: Theory and Practice. Environmental Science and Technology 34(8): 1396-1400
Hammitt K, Ibarrarán E (2006) The Economic Value of Fatal and Non-Fatal Occupational Risks in Mexico City using Actuarial and Perceived Risk Estimates. Health Economics 15(12): 1329-1335

Holland W, Bennett E, Cameron R, Florey V, Leeder R, Schilling S, Swan V, Waller E (1979) Health Effects of Particulate Pollution: Re-appraising the Evidence. American Journal of Epidemiology 110(5): 527659

Kaul S, Boyle K, Kuminoff N, Parmeter C, Pope J (2012) What Can We Learn From Benefit Transfer Errors? Evidence from 20 Years of Research on Convergent Validity. Available online at http://www.public.asu.edu/ nkuminof/KBKPP11.pdf

Khatun A (1997) The Cost of Particulate Air Pollution in Dhaka City. The Bangladesh Development Studies, XXV $(1 / 2)$

Kochi I, Hubbell B, Kramer R (2006) An Empirical Bayes Approach to Combining and Comparing Estimates of the Value of a Statistical Life for Environmental Policy Analysis. Environmental and Resource Economics 34(3): 385-406

Krupnick A, Harrison K, Nickell E, Toman M (1993) The Benefits of Ambient Air Quality Improvements in Central and Eastern Europe: A Preliminary Assessment (Discussion Paper ENR93 - 19). Resources for the Future, Washingon, D.C

Krzyzanowski M (2008) WHO Air Quality Guidelines for Europe. Journal of Toxicology and Environmental Health, Part A , 71(1): 47-50

Krzyzanowski M, Cohen A, Anderson R (2002) Quantification of the Health Effects of Exposure to Air Pollution. Occupational and Environmental Medicine 59(12): 791-793

Larson B, Avaliani S, Golub A, Rosen S, Shaposhnikov D, Strukova E, Vincent J, Wolff S (1999) The Economics of Air Pollution Health Risks in Russia: A Case Study of Volgograd. World Development 27(10): 1803-1819

Madheswaran S (2007) Measuring the Value of Statistical Life: Estimating Compensating Wage Differentials among Workers in India. Social Indicators Research 84(1): 83-96

Manning W, Mullahy J (2001) Estimating Log Models: To Transform or Not to Transform? Journal of Health Economics 20(4): 461-494

Melhuish C, Ross A, Goodge M, Mani K, Yussof M, Umar R (2005) Accident Costing Report: AC5, The Cost of Road Traffic Accidents in Malaysia. Asian Development Bank - Association of Southeast Asian Nations, Regional Road Safety Program. Available via http://www.adb.org/documents/reports/arrivealive/costing-reports/costing-rep-05-mal.pdf

Miller T (2000) Variations between Countries in Values of Statistical Life. Journal of Transport Economics and Policy 34(Part 2): 169-188 
Muller N, Mendelsohn R (2007) Measuring the Damages of Air Pollution in the United States. Journal of Environmental Economics and Management 54(1): 01-14

Navrud S, Ready R (2007) Review of Methods for Value Transfer. In: Navrud S, Ready R (Eds.) (2007) Environmental Value Transfer: Issues and Methods. Springer, The Netherlands

Nelson J, Kennedy P (2009) The Use (and Abuse) of Meta-Analysis in Environmental and Natural Resource Economics: An Assessment. Environmental and Resource Economics 42(3): 345-77

Ortuzar D, Cifuentes A, Williams L (2000) Application of Willingness-to-Pay Methods to Value Transport Externalities in Less Developed Countries. Environment and Planning A 32(11): 20072018

Ostro B (1994) Estimating Health Effects of Air Pollutants: A Methodology with an Application to Jakarta. Policy Research Working Paper 1301. World Bank, Washington, D.C.

(2001) Implications and Use of Time Series Mortality Studies for Health Impact Assessment. United Nations Economic Commission for Europe (IN/ECE), Convention on Long-range Transboundary Air Pollution, London, February 19

Pearce DW (1996) Economic Valuation and Health Damage from Air Pollution in the Developing World Energy Policy 24(7): 627-630

Pearce W, Whittington D, Georgiou S, James D (1994) Project and Policy Appraisal: Integrating Economics and Environment. Organisation for Economic Co-operation and Development (OECD), Paris

Phalen R (2002) The Particulate Air Pollution Controversy: A Case Study and Lessons Learned. Kluwer Academic Publishers, Boston/Dordrecht/London

(2004) The Particulate Air Pollution Controversy. Nonlinearity in Biology, Toxicology and Medicine 2(4): 259-292

Pope CA III (2007) Mortality Effects of Longer Term Exposures to Fine Particulate Air Pollution: Review of Recent Epidemiological Evidence. Inhalation Toxicology 19(Suppl. 1): 33-38

Pope CA III, Dockery W (1994) Acute Respiratory Effects of Particulate Air Pollution. Annual Review of Public Health 15: 107-132

Pope CA III, Bates D, Raizenne M (1995) Health Effects of Particulate Air Pollution: Time for Reassessment. Environmental Health Perspectives 103(5): 472-480

Quah E, Boon T (2003) The Economic Cost of Particulate Air Pollution on Health in Singapore. Journal of Asian Economics 14(1): 73-90

Resosudarmo B, Napitupulu L (2004) Health and Economic Impact of Air Pollution in Jakarta. The Economic Record 80(Special Issue): S65-S75
Robinson L, Hammitt J (2009) The Value of Reducing Air Pollution Risks in Sub-Saharan Africa. A final report prepared for the World Bank Sub-Saharan African Refinery Study. Available via http://www.regulatory-analysis.com/robinson-hammitt-air-pollution-africa.pdf

Rosenberger R, Loomis J (2003) Benefit Transfer. In Champ P, Boyle K, Brown T (2003) A Primer on Nonmarket Valuation. Kluwer Academic Publishers, Dordrecht, the Netherlands

Ruckerl R, Schneider A, Breitner S, Cyrys J, Peters A (2011) Health Effects of Particulate Air Pollution: A Review of Epidemiological Evidence. Journal of Inhalation Toxology 23(10): 555-592

Sakulniyomporn S, Kubaha K, Chullabodhi C (2010) Estimating the Health Damage Costs of Electricity Generation in Thailand. http://ieeexplore.ieee.org/stamp/stamp.jsp?tp=\&arnumber=5598854

Schwartz J (1991) Particulate Air Pollution and Daily Mortality in Detroit. Environmental Research 56(2): 204-213

(2000) Harvesting and Long-term Exposure Effects in the Relation between Air Pollution and Mortality. American Journal of Epidemiology 151(5): 440-448

(2001) Is there Harvesting in the Association of Airborne Particles with Daily Deaths and Hospital Admissions? Epidemiology 12(1): 55-61

(2003) Daily Deaths Associated with Air Pollution in Six US Cities and Short-term Mortality Displacement in Boston. In: Pope CA III (2007) Mortality Effects of Longer Term Exposures to Fine Particulate Air Pollution: Review of Recent Epidemiological Evidence. Inhalation Toxicology 19 (Suppl. 1): 33-38

Schwartz J, Dockery W (1992) Increased Mortality in Philadelphia Associated with Daily Air Pollution Concentrations. American Review of Respiratory Disease 145(3): 600-604

Schrenk H, Heimann H, Clayton D, Gafafer M, Wexler H (1949) Air Pollution in Donora, Pa.: Epidemiology of the Unusual Smog Episode of October 1948. Public Health Service, Washington, D.C

Shy CM (1979) Epidemiological Evidence and the US Air Quality Standards. American Journal of Epidemiology 110: 525-659

Smith V, Van Houtven G, Pattanayak S (2002) Benefit Transfer via Preference Calibration: "Prudentia Algebra" for Policy. Land Economics 78(1): 132-152

Stern C (1977) The Effects of Air Pollution, 3 edn. Academic Press, New York

United Nations Statistics Division (2010) Social Indicators - Indicators on Education. School Life Expenctancy (in Years): Primary to Tertiary Education. Available via http://unstats.un.org/unsd/demographic/products/socind/education.htm

USEPA (2004) Value of Statistical Life Analysis and Environmental Policy: A White Paper. USEPA, Washingon, DC 
Vassanadumrongdee S, Matsuoka S (2005) Risk Perceptions and Value of a Statistical Life for Air Pollution and Traffic Accidents: Evidence from Bangkok, Thailand. Journal of Risk and Uncertainty 30(3): 261287

Viscusi KW (2004) The Value of Life: Estimates with Risks by Occupation and Industry. Economic Inquiry 42(1): 29-48

(2011) What's to Know? Puzzles in the Literature on the Value of Statistical Life. Journal of Economic Surveys, forthcoming.

Viscusi KW, Aldy J (2003) The Value of Statistical Life: A Critical Review of Market Estimates Throughout the World. Journal of Risk and Uncertainty 27(1): 05-76

(2007) Age Differences in the Value of Statistical Life: Revealed Preference Evidence. Review of Economics and Policy 1(2): 241-260

Wang H, He J (2010) The Value of Statistical Life: A Contingent Evaluation in China. The World Bank Policy Research Working Paper; no WPS 5421

Wang H, Mullahy J (2006) Willingness to Pay for Reducing Fatal Risk by Improving Air Quality: A Contingent Valuation Study in Chongqing, China. Science of the Total Environment 367(1): 50-57

Wooldridge MJ (2008) Introductory Econometrics: A Modern Approach. Thomson South-Western

World Bank (2010) World Development Indicators, September 2010 Edition. Available via http://web.worldbank.org/

World Health Organisation (2003) Health Aspects of Air Pollution with Particulate Matter, Ozone and Nitrogen Dioxide. Report on a WHO Working Group; Bonn, Germany. Available via http://www.euro.who.int/Document/e79097.pdf

(2005) WHO Air Quality Guidelines for Particulate Matter, Ozone, Nitrogen Dioxide and Sulphur Dioxide. Global Update 2005: Summary of Risk Assessment. Available via http://whqlibdoc.who.int/hq/2006/WHO_SDE_PHE_OEH_06.02_eng.pdf

(2009) Table1: Estimated Total Deaths ('000), by Cause and WHO Member State, 2004 (a). Available

http://www.who.int/healthinfo/global_burden_disease/estimates_country/en/index.html

Zaim K (1999) Modified GDP through the Health Cost Analysis of Air Pollution: The Case of Turkey. Environmental Management 23(2): 271-277

Zhang M, Song Y, Cai X, Zhou J (2008) Economic Assessment of the Health Effects Related to Particulate Matter Pollution in 111 Chinese Cities by Using Economic Burden of Disease Analysis. Journal of Environmental Management 88(4): 497-954

Zhou Y, Tol R (2005) Valuing the Health Impacts from Particulate Air Pollution in Tianjin. Working Paper FNU - 89, Research Unit on Sustainability and Climate Change. Hamburg University and Centre for Marine and Atmospheric Science 